\title{
Contributions of the Hadley and Ferrel Circulations to the Energetics of the Atmosphere over the Past 32 Years*
}

\author{
Junling Huang AND Michael B. McElroy \\ School of Engineering and Applied Sciences, Harvard University, Cambridge, Massachusetts
}

(Manuscript received 3 September 2013, in final form 21 November 2013)

\begin{abstract}
The Hadley system provides an example of a thermally direct circulation; the Ferrel system in contrast provides an example of a thermally indirect circulation. In this study, the authors develop an approach to investigate the key thermodynamic properties of the Hadley and Ferrel systems, quantifying them using assimilated meteorological data covering the period January 1979-December 2010. This analysis offers a fresh perspective on the conversion of energy in the atmosphere from diabatic heating to the production of atmospheric kinetic energy. The results indicate that the thermodynamic efficiency of the Hadley system, considered as a heat engine, has been relatively constant over the 32-yr period covered by the analysis, averaging $2.6 \%$. Over the same interval, the power generated by the Hadley regime has risen at an average rate of about $0.54 \mathrm{TW} \mathrm{yr}^{-1}$; this reflects an increase in energy input to the system consistent with the observed trend in the tropical sea surface temperatures. The Ferrel system acts as a heat pump with a coefficient of performance of 12.1, consuming kinetic energy at an approximate rate of $275 \mathrm{TW}$ and exceeding the power production rate of the Hadley system by 77 TW.
\end{abstract}

\section{Introduction}

The Lorenz energy cycle (Lorenz 1955) provides an instructive approach to a quantitative investigation of the energetics of the atmosphere. The uneven spatial distribution of diabatic heating in the atmosphere results in an increase in available potential energy that is converted consequently to kinetic energy maintaining the circulation of the atmosphere against friction. Grounded on this theory, creation of kinetic energy at the expense of available potential energy can be decomposed into a contribution from the meridional overturning circulation, denoted as $C_{Z}$, and a contribution from eddies, denoted as $C_{E}$. Several groups (e.g., Krueger et al. 1965; Wiin-Nielsen 1967; Oort 1964; Oort and Peixoto 1974; Oort 1983; Li et al. 2007; Kim and Kim 2013) have sought

๖ Denotes Open Access content.

\footnotetext{
* Supplemental information related to this paper is available at the Journals Online website: http://dx.doi.org/10.1175/JCLI-D-1300538.s1.

Corresponding author address: Michael B. McElroy, School of Engineering and Applied Sciences, Harvard University, 29 Oxford St., Cambridge, MA 02138.

E-mail:mbm@seas.harvard.edu
}

to analyze the energetics of the atmosphere following this approach. Based on daily reports from the global radiosonde network for the 10 -yr period from 1963 to 1973, Oort (1983) estimated $C_{Z}$ and $C_{E}$ as -0.15 and $2.0 \mathrm{~W} \mathrm{~m}^{-2}$, respectively, revealing the dominant role of $C_{E}$ relative to $C_{Z}$, and concluded that the indirect Ferrel circulation consumes zonal mean kinetic energy at a rate slightly exceeding production by the Hadley circulation. The importance of $C_{E}$ and $C_{Z}$ in the conversion of available potential energy to kinetic energy is confirmed by recent studies based on assimilated datasets including National Centers for Environmental Prediction-National Center for Atmospheric Research (NCEP-NCAR) reanalysis, NCEP-U.S. Department of Energy (DOE) Atmospheric Model Intercomparison Project phase 2 (AMIP-II) reanalysis (NCEP-R2), 40-yr European Centre for Medium-Range Weather Forecasts (ECMWF) Re-Analysis (ERA-40), and Modern-Era Retrospective Analysis for Research and Applications (MERRA). There are discrepancies, however, in the absolute value and the sign of $C_{Z}$ (Li et al. 2007; Kim and $\operatorname{Kim} 2013)$. Here $C_{Z}$ refers to a composite of three meridional overturning components: the Hadley system in the tropics, the Ferrel system in the midlatitudes, and the polar system at high-latitude regions. An in-depth understanding of $C_{Z}$ requires an independent analysis of each component. The Lorenz energy cycle has limitations 
when it comes to defining the role of individual sources in the creation of kinetic energy: it is unable, for example, to isolate the contribution from the Hadley circulation.

The Hadley circulation is identified with rising of warm and moist air in the equatorial region with the descent of colder air in the subtropics corresponding to a thermally driven direct circulation, with consequent net production of kinetic energy. Many studies (e.g., Mitas and Clement 2005, 2006; Frierson et al. 2007; Hu and Fu 2007; Lu et al. 2007; Previdi and Liepert 2007; Seidel and Randel 2007; Seidel et al. 2008; Johanson and Fu 2009; Stachnik and Schumacher 2011; Davis and Rosenlof 2012; Nguyen et al. 2013; Hu et al. 2013) have sought to analyze how the Hadley system has varied under the recent warming climate. Results from these investigations indicate expansion and intensification of the Hadley circulation over the past several decades. A related question is whether the Hadley system has become more energetic.

At the midlatitudes, the circulation of the atmosphere is dominated by wavelike flows. The Ferrel cells represent statistical residues, which result after zonal averaging of large northward and southward flows associated with the quasi-stationary atmospheric waves. The Ferrel cells are identified with the rising motion of relatively cold air at high latitudes and the sinking of relatively warm air at the lower midlatitudes, thus, defining a thermally indirect circulation with consequent consumption of kinetic energy (Peixoto and Oort 1992).

Grotjahn (2003) pointed out that the Carnot cycle concept can be used to estimate the generation of kinetic energy that results from the thermodynamic changes an air parcel undergoes while completing an atmospheric circuit. He estimated the power of one of the Hadley cells by plotting the thermodynamic properties of air parcels on a temperature-pressure diagram. In this study, we extend his approach, investigating the key thermodynamic properties of the Hadley and Ferrel circulations using assimilated meteorological data from MERRA. The analysis allows us to differentiate individual contributions of the Hadley and Ferrel systems to the $C_{Z}$ process. As will be shown, the study indicates an upward trend in the power generated by the Hadley system over the past three decades, consistent with view that this system is strengthening.

\section{Data and methodology}

This investigation is based on meteorological data from the MERRA compilation covering the period January 1979-December 2010. Wind speeds, air temperature, and geopotential heights were obtained on the basis of retrospective analysis of global meteorological data using the Goddard Earth Observing System, version 5.2.0 (GEOS-5) Data Assimilation System (DAS). We use the standard monthly output available for 42 pressure levels with a horizontal resolution of $1.25^{\circ}$ latitude $\times 1.25^{\circ}$ longitude (Rienecker et al. 2007). The tropical sea surface temperature and ENSO index is from the Goddard Institute for Space Studies (Hansen et al. 1999, 2010).

Streamfunctions defining the zonal mean circulation were computed using the continuity equation for mass expressed in the zonally averaged form:

$$
\frac{\partial[\bar{v}] \cos \Phi}{R \cos \Phi \partial \Phi}+\frac{\partial[\bar{\omega}]}{\partial P}=0,
$$

where $\left[^{-}\right]$defines the time and zonal average operator, $v$ is the meridional wind speed (in units of $\mathrm{m} \mathrm{s}^{-1}$ ), $\omega$ is the vertical wind speed (in units of $\mathrm{Pa} \mathrm{s}^{-1}$ ), $\Phi$ is latitude, and $P$ is pressure (in $\mathrm{Pa}$ ).

The mass streamfunction $\varphi$ is then given by

$$
\begin{aligned}
& {[\bar{v}]=g \frac{\partial \varphi}{2 \pi R \cos \Phi \partial P} \text { and }} \\
& {[\bar{\omega}]=-g \frac{\partial \varphi}{2 \pi R^{2} \cos \Phi \partial \Phi} .}
\end{aligned}
$$

We calculated $\varphi$ using $[\bar{v}]$, while $[\bar{\omega}]$ was computed on the basis of the assimilated meteorological data through the horizontal integration of Eq. (2) combined with the vertical integration of Eq. (3) beginning at the top of the atmosphere where we assumed $\varphi=0$.

\section{Thermodynamic properties of the Hadley system}

\section{a. Illustration of a direct thermal circulation}

Values for January 2009 mass streamfunction $\left(10^{9} \mathrm{~kg} \mathrm{~s}^{-1}\right)$, computed on the basis of the zonal average of monthly assimilated meteorological data, are presented in Fig. 1a. Positive values are indicated by warm (red) colors with negative values denoted by cold (blue) colors. The thick black contour illustrates the direction of motion (white arrows) corresponding to the direct thermal circulation of the Hadley regime. Maximum heating in January 2009 occurs south of the equator. The air is less dense as a consequence, rising due to buoyancy, cooling in the process. Reaching the top of the convection cell, the air moves northward, cooling as it radiates more energy than it absorbs before sinking eventually in the northern subtropics (Marshall and Plumb 2008). The loop is completed as the air moves back across the equator at the surface.

As an example of how work is produced by completing travel around one loop of the cell, we selected the segment defined by the thick black contour in Fig. 1a, 
(a) January 2009 mass stream function $\left(10^{9} \mathrm{~kg} \mathrm{~s}^{-1}\right)$
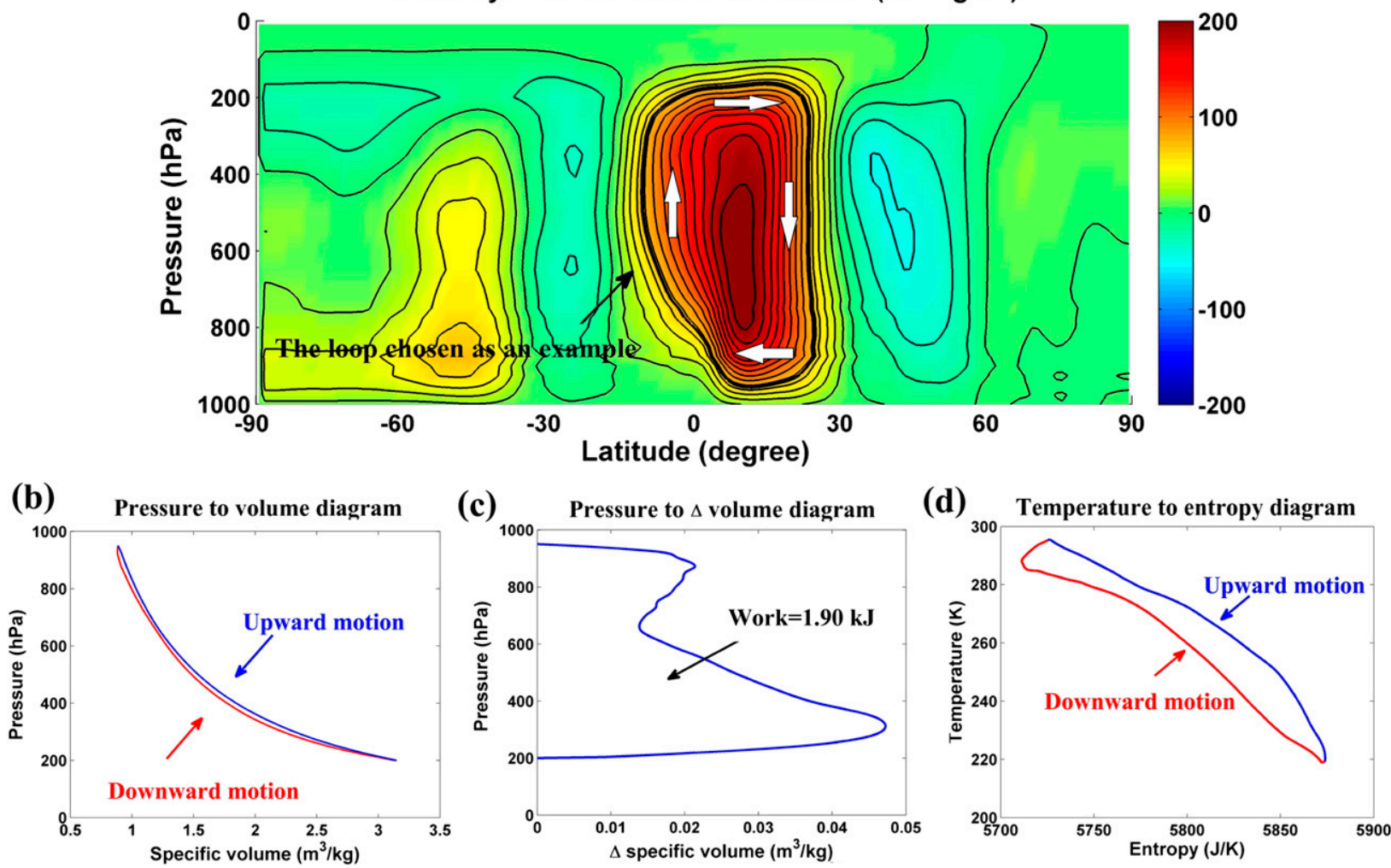

FIG. 1. The average meridional circulation of the atmosphere in January 2009 with an emphasis on the direct Hadley system. (a) Color shading specifies the mass streamfunction values $\left(10^{9} \mathrm{~kg} \mathrm{~s}^{-1}\right)$. The thick black loop with a constant mass streamfunction value of $70 \times$ $10^{9} \mathrm{~kg} \mathrm{~s}^{-1}$ is chosen as an example to illustrate the thermally driven direct circulation. White arrows point in the direction of the air motion. The (b) $P-V$, (c) $P-\Delta V$, and (d) $T-S$ diagrams for an air parcel with the example mass streamfunction value.

corresponding to a constant mass streamfunction value of $70 \times 10^{9} \mathrm{~kg} \mathrm{~s}^{-1}$. The pressure-volume $(P-V)$ diagram for the transit of $1 \mathrm{~kg}$ of air around this loop is presented in Fig. $1 \mathrm{~b}$. At a given pressure level, while the air parcel is experiencing ascending motion, its specific volume (illustrated by the blue line) is always greater than the specific volume (expressed by the red line) associated with the descending portion of the trajectory. The area inside the loop defines the network performed by the air parcel as it completes travel along the indicated loop. The network obtained by completing one circuit of the loop is given by $\oint P d V_{s}$ where $V_{s}$ defines the specific volume of the air parcel.

The network performed by the air parcel in completing this loop is estimated at $1.90 \mathrm{~kJ}$. The corresponding pressure- $\Delta$ volume $(P-\Delta V)$ diagram is presented in Fig. 1c in which the vertical axis indicates pressure, with the specific volume change identified on the horizontal axis (at a given pressure level, the specific volume associated the ascending motion minus the specific volume associated with descending motion). The positive sign of $\Delta V_{s}$ in Fig. $1 \mathrm{c}$ implies a positive network. Figure $1 \mathrm{~d}$ presents the temperature-entropy $(T-S)$ diagram for this air parcel, illustrating the changes in temperature and specific entropy that develop over a thermodynamic cycle. The red portion of the temperature-entropy cycle is associated with the downward motion, and located quite close to the blue portion associated with the upward motion, indicating a small thermodynamic efficiency. The thermodynamic efficiency $\eta$ of the loop is defined by

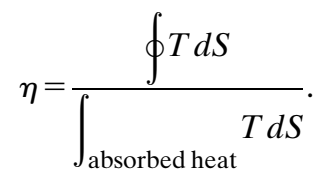

The integral of absorbed heat in the denominator is restricted to portions of the cycle corresponding to net positive heating (namely $T d S>0$ ). The entropy term can be computed as $S=c_{p} \ln \theta$, where $c_{p}$ is the specific heat of dry air at constant pressure and $\theta$ is potential temperature.

According to the second law of thermodynamics, $d Q=T d S$, where $d Q$ is the net heat contributed by 
(a)

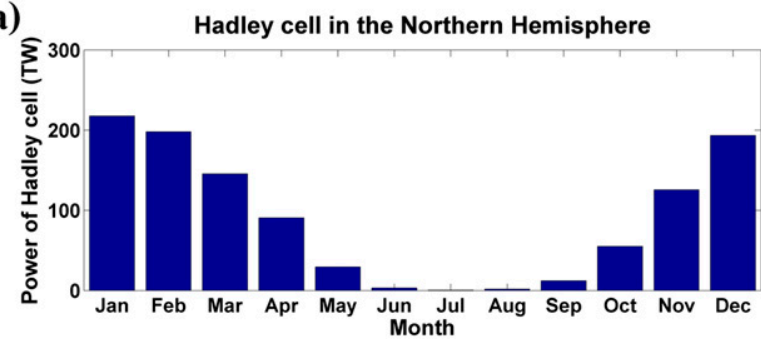

(b)

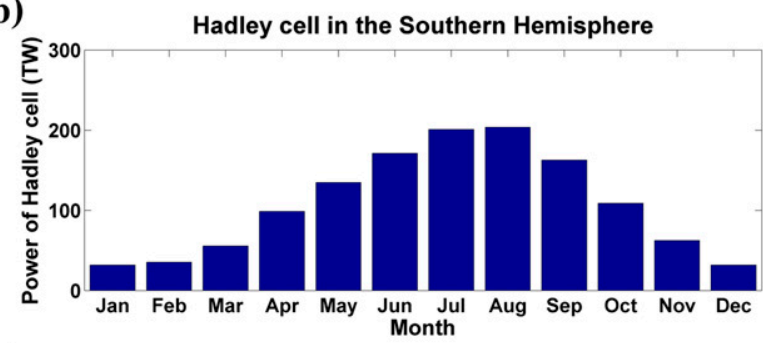

(c)

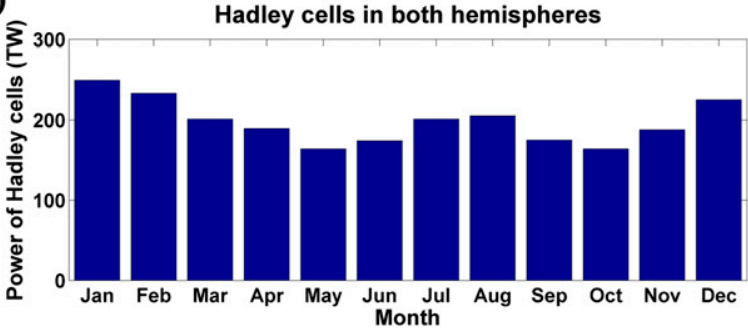

(d)

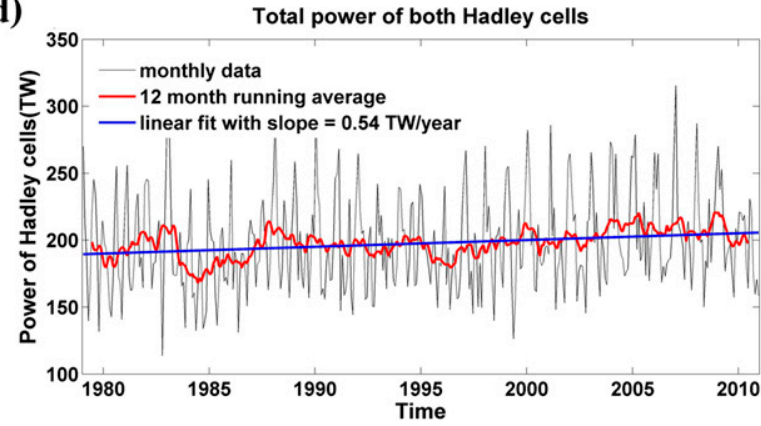

FIG. 2. The power of the Hadley circulation as a function of month in (a) the Northern Hemisphere and (b) the Southern Hemisphere, and (c) the total power of both Hadley cells. (d) The variation of the total power of both Hadley cells by year from January 1979 to December 2010.

various sources including radiative heating (solar and infrared) and the release of latent heat. Thus, the denominator in Eq. (4) calculates the net heat absorbed by the air parcel at a higher temperature in order to do the mechanical work. Water vapor in the atmosphere acts as a means of storing heat that can be released later. As the air ascends, it may cool and become saturated; then water vapor condenses releasing latent heat. In the case of the tropical atmosphere, the heat $d Q$ is dominated by the release of latent heat (James 1995). For the loop (a)

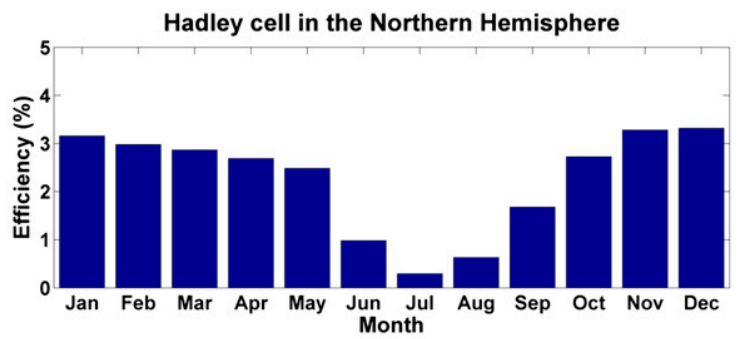

(b)

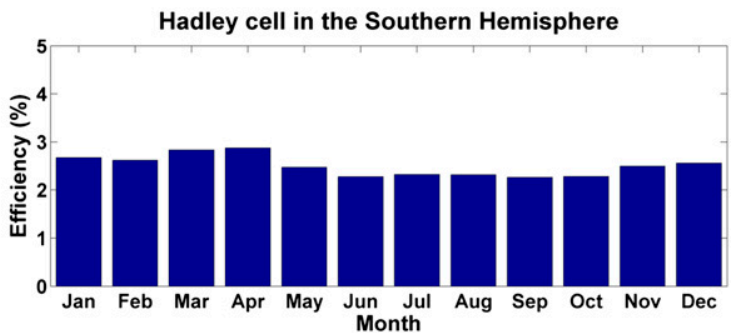

(c)



(d)

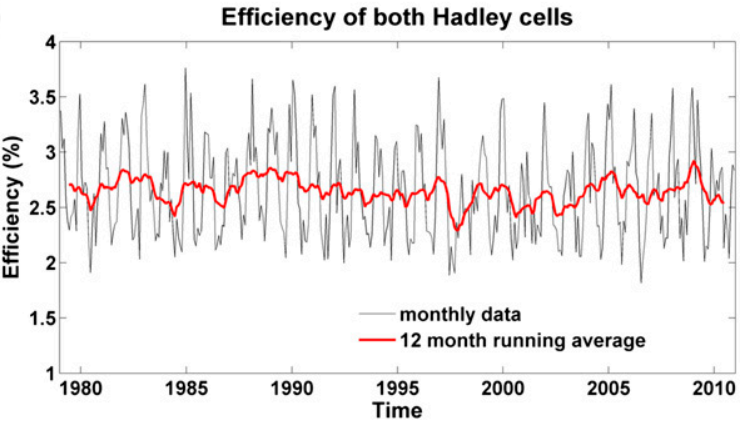

FIG. 3. As in Fig. 2, but for the efficiency of the Hadley circulation.

considered here, the thermodynamic efficiency is about $4.3 \%$. Only a small fraction of the heat supplied to the air parcel is converted to mechanical energy.

\section{b. Power of the Hadley system}

Consider two loops with constant streamfunction values, one inside the other (see Fig. S1 in the supplementary material). Assume that the total mass between loops 1 and 2 is represented by $M$, while the average time required to complete travel through the region sandwiched between loops 1 and 2 is expressed by $t$. The mass flux, denoted by $F$, between loops 1 and 2 is given by the difference between the mass streamfunction values for loops 1 and 2 . The network associated with 
(a)

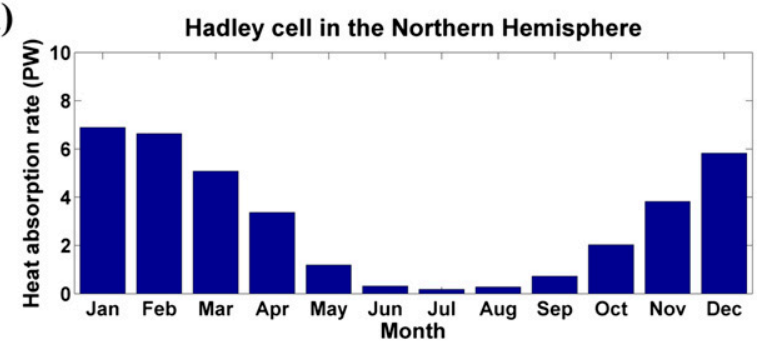

(b)

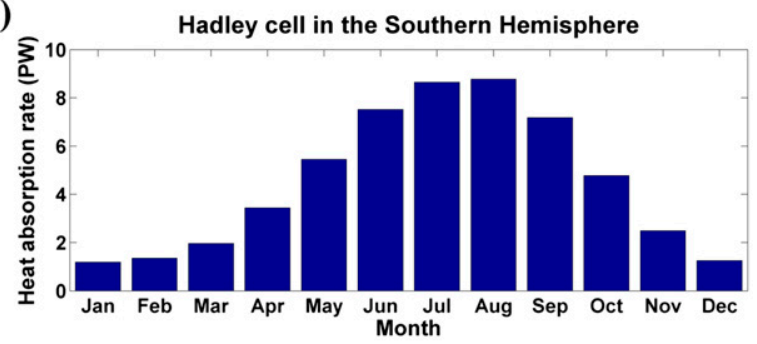

(c)

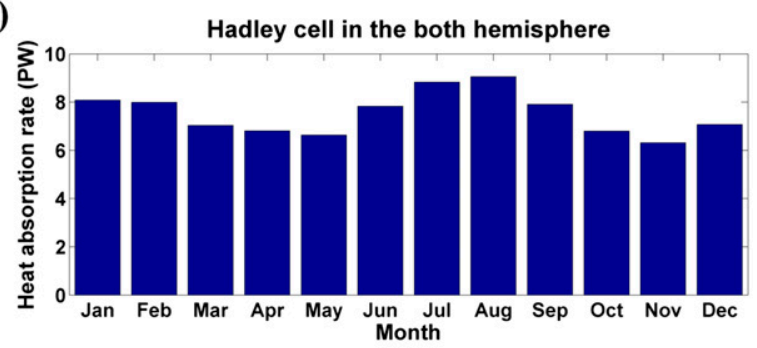

(d)

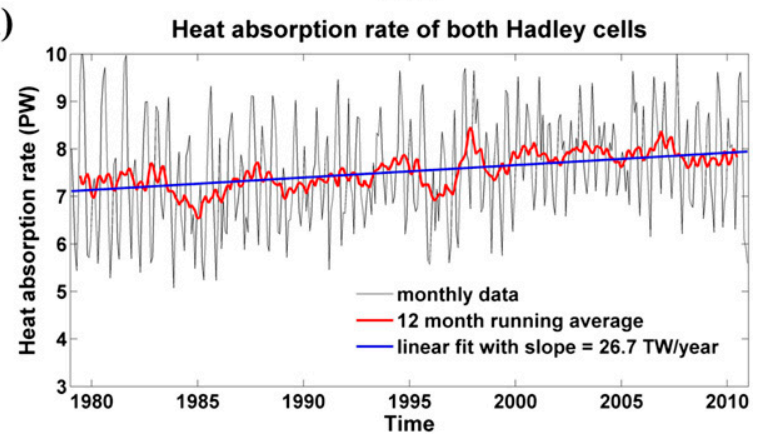

FIG. 4. As in Fig. 2, but for the heat absorption rate of the Hadley circulation.

travel through one complete loop is defined by $M \oint P d V_{S}$, while the time required to travel along the loop is given by $t=M / F$. Thus, the power generated by the motion of the air sandwiched between loops 1 and 2 is specified by $F \oint P d V$.

For each Hadley cell, the associated power may be calculated according to

\section{Power}

$$
=\int_{\text {center of the cell }}^{\text {edge of the cell }} \frac{\partial(\text { Stream function value })}{\partial \Phi} \oint P d V \times d \Phi .
$$

(a)

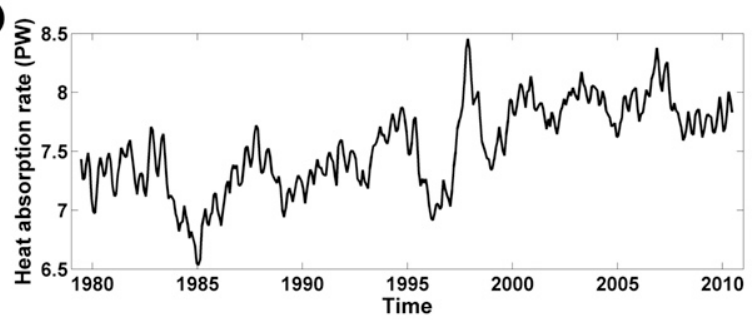

(b)

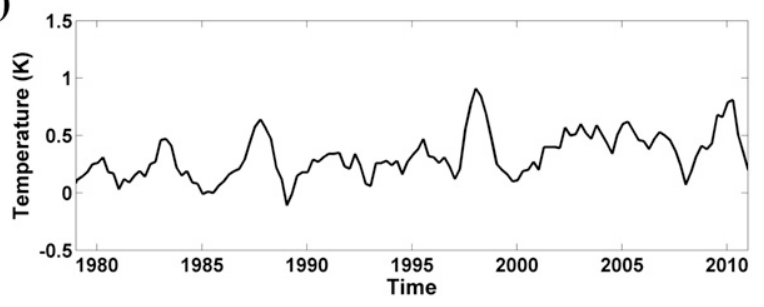

(c)

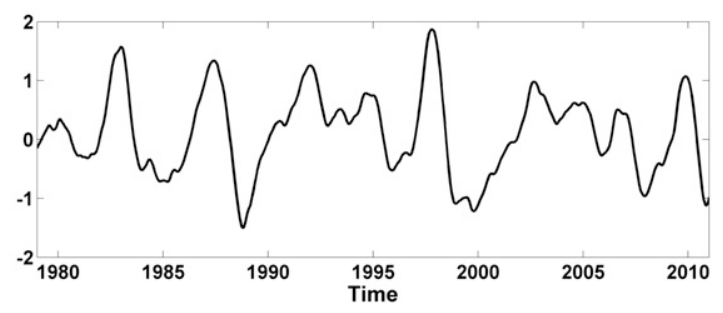

FIG. 5. Variations of heat absorption rates of (top-bottom) both Hadley cells, low-latitude temperatures, and the ENSO index: (a) 12-month running average of the total heat absorption rate for both Hadley cells from January 1979 to December 2010, (b) changes in mean tropical temperature (data available at http://data.giss.nasa. gov/gistemp) over the period January 1979-December 2010, and (c) Niño-3.4 index (data available at http://www.esrl.noaa.gov/psd/ data/climateindices) over the period January 1979-December 2010 .

Based on the assimilated meteorological data adopted here to define conditions over the past 32 years, we calculated the power of the Hadley cells in each hemisphere as well as their combination. The composite (32-yr average) monthly results are presented in Figs. 2a-c. The Hadley cell identified for the Northern Hemisphere refers to the entire cell originating in the Southern Hemisphere extending across the equator to the Northern Hemisphere during the Northern Hemispheric winter. A similar definition applies to the Hadley cell in the Southern Hemisphere. The Hadley cell in the Northern Hemisphere, not surprisingly, reaches its peak power of $218 \mathrm{TW}$ in January with a minimum of $0.5 \mathrm{TW}$ in July. The counterpart in the Southern Hemisphere has a peak of 204 TW in August with a minimum of $32 \mathrm{TW}$ in January. Considering the power associated with the combination of both Hadley cells, there are two peaks of $250 \mathrm{TW}$ in January and $205 \mathrm{TW}$ in August, and two minima of 164 TW in May and 164 

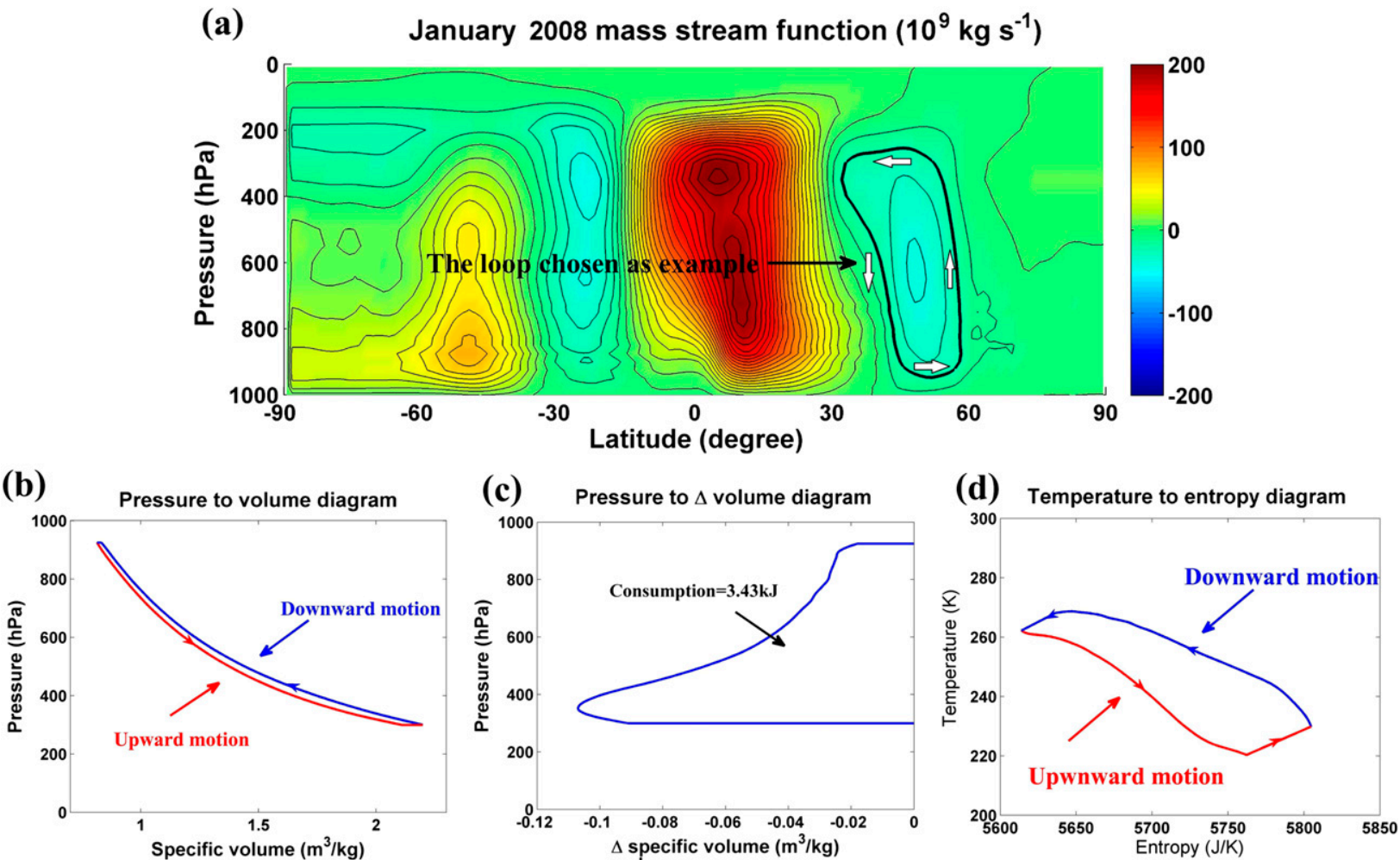

FIG. 6. As in Fig. 1, but for the average meridional overturning of the atmosphere in January 2008 with an emphasis on the indirect Ferrel circulation and with the thick black loop having a streamfunction value of $-20 \times 10^{9} \mathrm{~kg} \mathrm{~s}^{-1}$

TW in October. The annual mean power associated with the overall Hadley system amounts to 198 TW. Reflecting differences in land-sea contrast between the hemispheres, the Hadley cell in the Northern Hemisphere almost disappears during the northern summer. Results for the power of the circulation obtained here are smaller than those reported earlier by Grotjahn (2003).

From Fig. 2 alone, it is unclear which of the terms in Eq. (5) dominates the annual cycle of Hadley cell power output. Oort and Rasmusson (1970) investigated the annual cycle of the Hadley circulation based on the value of the mass streamfunction and data for a 5-yr period obtained from a dense network of upper-air stations. The seasonality of the Hadley system was explored further by Dima and Wallace (2003) using NCEP-NCAR data covering the period 1979-2001. Defining the seasonality as the principal component of the first EOF mode of the mass streamfunction, Dima and Wallace concluded that the seasonal variation of the circulation is sinusoidal. The functional similarity between these results and the seasonal cycle in Fig. 2 implies that large absolute values of the mass streamfunction are normally associated with large power output of the Hadley system and vice versa.

The long-term variation of the power contributed by both cells is plotted in Fig. 2d, covering the period January 1979-December 2010. The conspicuous intraseasonal fluctuation in the black line reflects the strong seasonal variation of the Hadley circulation. The red line, computed using a 12-month running average, indicates the existence of an interannual variation combined with a longer-term intensification of the circulation. Linear regression of the annual mean average data indicates an increase of $0.54 \mathrm{TW} \mathrm{yr}^{-1}$ in total power since 1979 as defined by the blue line. The associated $R^{2}$ for the regression analysis however is 0.31 , indicating considerable uncertainty in the magnitude of the inferred trend.

\section{c. Thermodynamic efficiency of the Hadley system}

The thermodynamic efficiency for the Hadley cell in converting heat to work can be quantified in terms of the ratio of the power generated by the cell with respect to the corresponding rate for net positive absorption of heat. The rate for absorption of heat is given by 
(a)

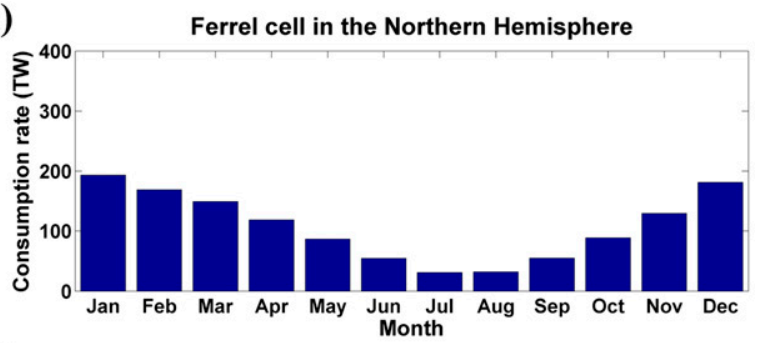

(b)

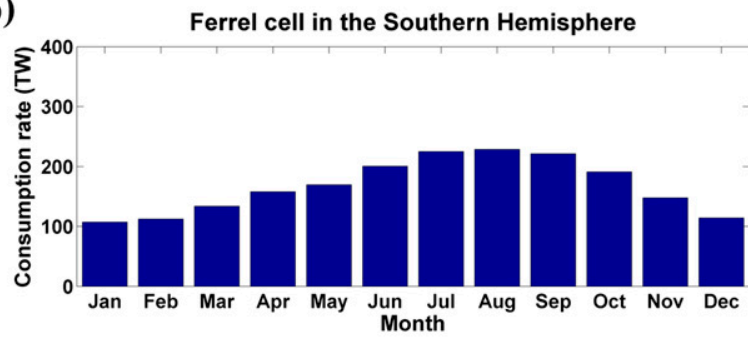

(c)

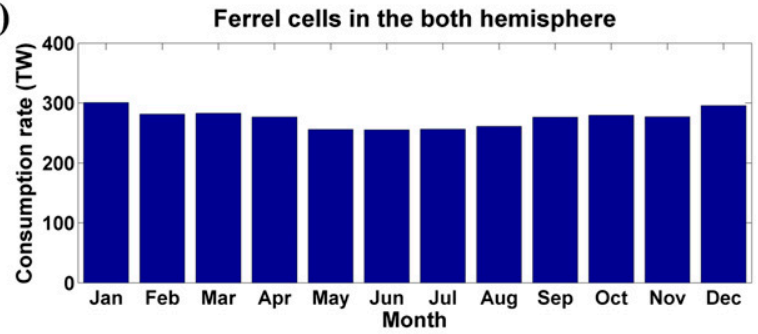

(d)

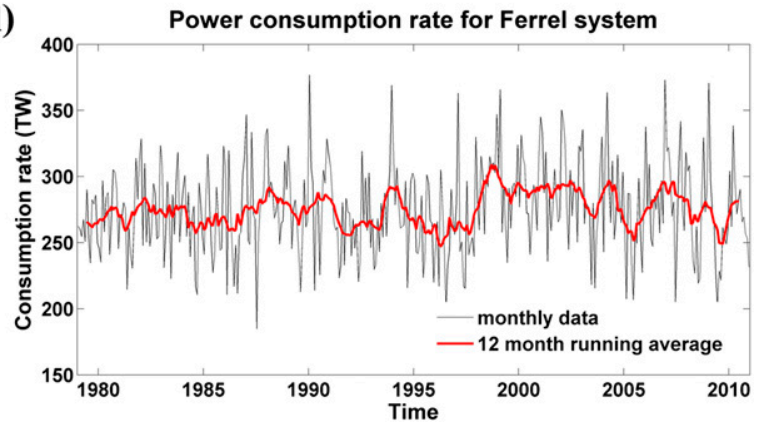

FIG. 7. As in Fig. 2, but for Ferrel circulation. (a)

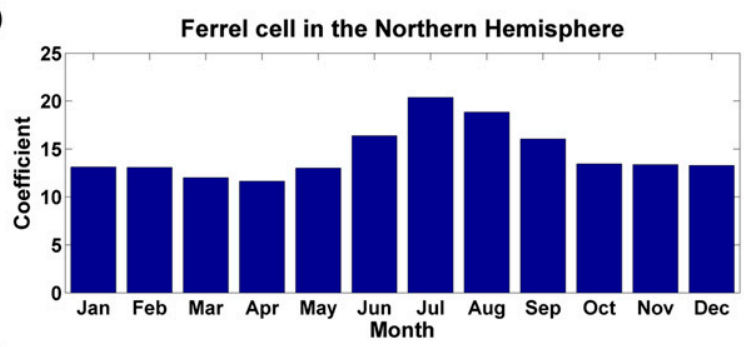

(b)

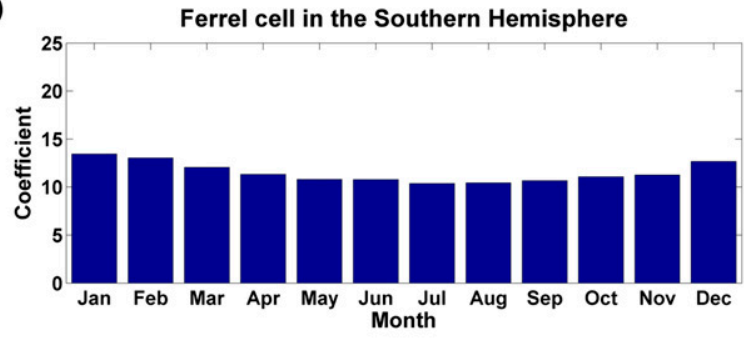

(c)

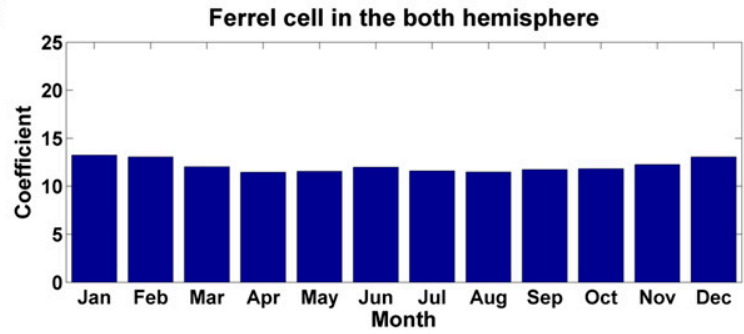

(d)

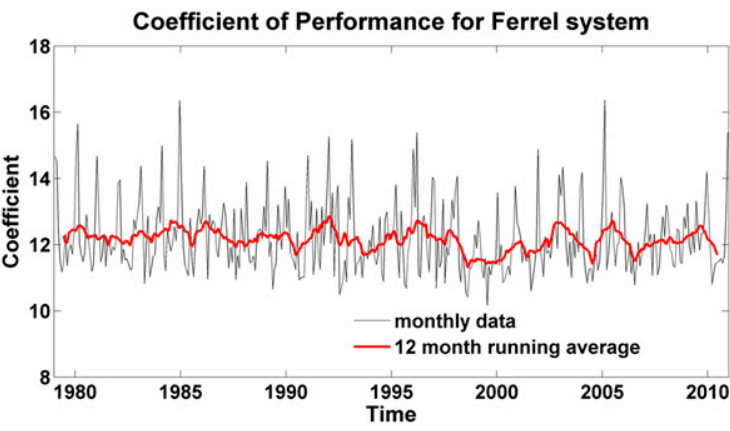

FIG. 8. As in Fig. 2, but for the COP of the Ferrel circulation.

$$
\text { absorption rate }=\int_{\text {center of the cell }}^{\text {edge of the cell }} \frac{\partial(\text { Stream function value })}{\partial \Phi} \int_{\text {absorded heat }} T d S \times d \Phi .
$$

Results for the thermodynamic efficiency of the Hadley cells in each hemisphere together with the overall efficiency of the entire circulation are displayed as a function of months in Figs. 3a-c. The Hadley cell in the Northern Hemisphere reaches its highest efficiency of $3.3 \%$ in December with a minimum of less than $0.3 \%$ in July. The counterpart in the Southern Hemisphere has a maximum efficiency of $2.9 \%$ in April with a minimum of $2.3 \%$ in June. The overall efficiency of the entire Hadley system is relatively constant, approximately $2.6 \%$ for each month, with a relatively small associated variation with season. The efficiency calculated for the entire Hadley system is weighted toward the stronger cell; thus, the $0.3 \%$ efficiency of the $\mathrm{NH}$ cell during July does not affect the overall efficiency of the Hadley system, given the fact that the Southern Hemisphere cell is exceptionally strong during this month.

Although the streamfunction term dominates, the thermodynamic efficiency plays an important role as well. Reanalysis datasets typically indicate higher values for the 
overturning streamfunction value in the Southern Hemisphere as compared to the Northern Hemisphere (Nguyen et al. 2013). However, the Hadley cell in the Northern Hemisphere has a slightly greater peak power with the associated efficiency of $3.2 \%$ as compared with the peak power of the corresponding cell in the Southern Hemisphere with an efficiency of $2.3 \%$, reflecting the importance of thermodynamic efficiency in determining the generation of power.

The long-term trend for the overall efficiency of the entire Hadley circulation is plotted in Fig. 3d for the period January 1979-December 2010. The strong fluctuation in the black line reflects the seasonal variation of the circulation. The red line, computed using a 12-month running average, suggests that, at least on an annually averaged basis, the efficiency has varied little over the $30-y r$ interval covered by the present analysis. Linear regression of the annual mean average over this period provides a regression slope of $-0.0029 \% \mathrm{yr}^{-1}$ with $R^{2}=$ 0.06 , indicating no statistically significant trend in thermodynamic efficiency.

Monthly values for the heat absorption rates for the Hadley cells in each hemisphere and for the entire Hadley circulation (an average over the entire record covered in this study) are presented in Figs. 4a-c. The long-term variation of the rate at which the heat is absorbed in driving the entire Hadley circulation is plotted in Fig. 4d for the period January 1979-December 2010. The linear regression of the annual mean average data indicates an upward trend with an increase rate of $26.7 \mathrm{TW} \mathrm{yr}^{-1}$ with $R^{2}=0.55$, as shown by the blue line. The interannual variation of the heat absorption rate is associated with variation in tropical sea surface temperature between $23.6^{\circ} \mathrm{S}$ and $23.6^{\circ} \mathrm{N}$ (Fig. 5b): high tropical sea surface temperatures (SSTs) correspond to high heat absorption rate, and vice versa. The correlation between the 12-month running average of the heat absorption rate and the tropical sea surface temperature shown in Fig. $5 b$ exceeds 0.6 , confirming their strong connection. The ENSO signal is evident also in the heat absorption rate: specifically the warm events in 1983, 1987, and 1997 , in addition to the cold events in 1985, 1996, and 1999 (Fig. 5c). The correlation between the heat absorption rate and the ENSO index shown in Fig. $5 \mathrm{c}$ is less, 0.32, presumably reflecting the fact that the ENSO phenomenon is more localized in the Pacific region rather than distributed over the entire domain of tropical latitudes.

\section{Thermodynamic properties of the Ferrel system}

\section{a. Illustration of an indirect thermal circulation}

As with section 3, we begin this section by highlighting one specific zonal mean cell. We choose a specific (a)

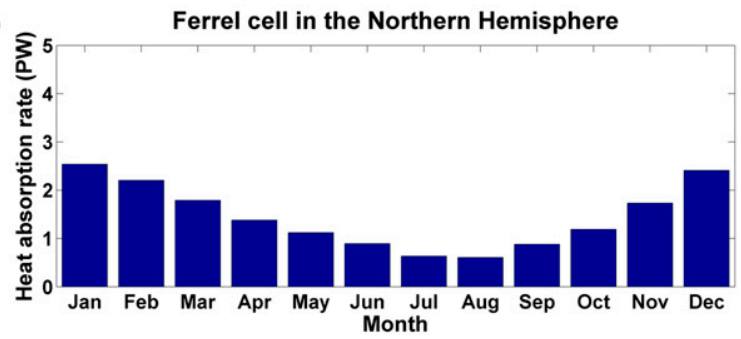

(b)

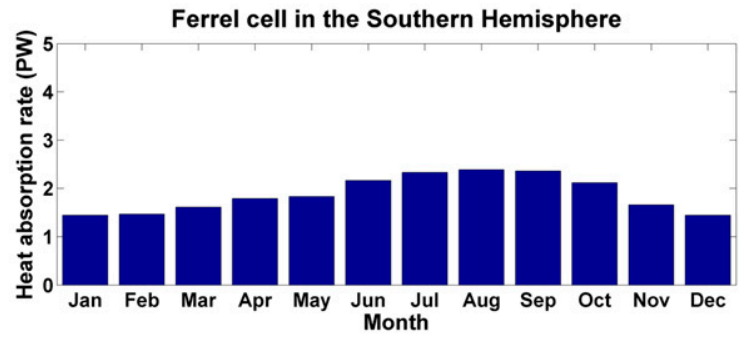

(c)

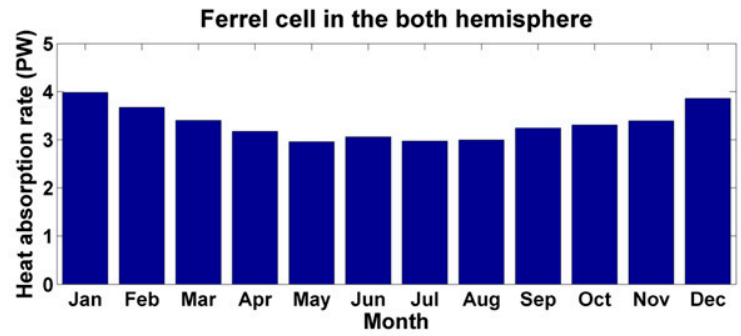

(d)



FIG. 9. As in Fig. 2, but for the heat absorption rate of the Ferrel circulation.

segment shown in Fig. 6a, defined by the thick black contour, with a constant mass streamfunction value of $-20 \times 10^{9} \mathrm{~kg} \mathrm{~s}^{-1}$. The $P-V$ diagram for transit of $1 \mathrm{~kg}$ around this loop is presented in Fig. 6b. In contrast to the Hadley circulation, while the air parcel is experiencing ascending motion, its specific volume (illustrated by the blue line) is always smaller than the specific volume (expressed by the red line) associated with the descending portion of the trajectory. The network consumed by the air parcel in completing this loop is estimated at $3.43 \mathrm{~kJ}$. The corresponding $P-\Delta V$ diagram is presented in Fig. 6c. The $T-S$ cycle in Fig. $6 \mathrm{~d}$ is much rounder than that in Fig. 1d, reflecting the stronger temperature contrast at midlatitudes, indicating the 


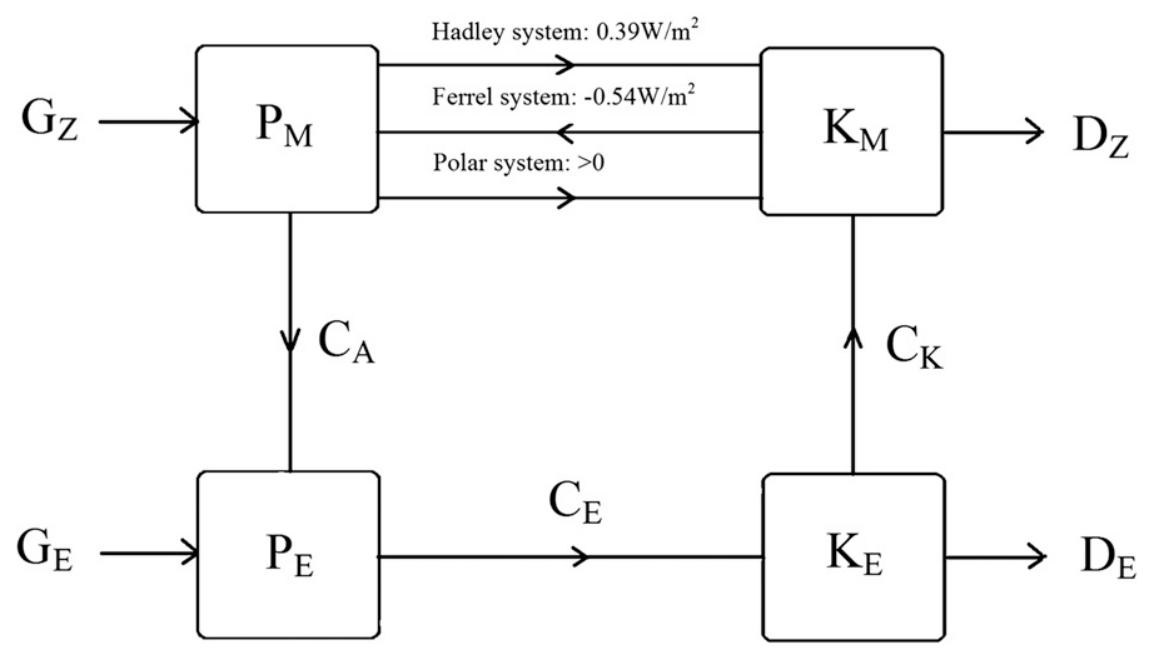

FIG. 10. Lorenz energy cycle with decomposition of the kinetic energy source $C_{Z}$. The quantity $P_{M}$ is the mean available potential energy, $P_{E}$ is the eddy available potential energy, $K_{M}$ is the mean kinetic energy, $K_{E}$ is the eddy kinetic energy, $G_{z}$ is the creation of $P_{M}, G_{E}$ is the creation of $P_{E}, C_{A}$ is the conversion from $P_{M}$ to $P_{E}, C_{E}$ is the conversion from $P_{E}$ to $K_{E}, C_{K}$ is the conversion from $K_{E}$ to $K_{M}, D_{z}$ is the dissipation of $K_{M}$, and $D_{E}$ is the dissipation of $K_{E}$.

high efficiency of the Ferrel system in consumption of kinetic energy (Lorenz 1967).

The coefficient of performance (COP) of the loop is defined by

$$
\mathrm{COP}=\frac{\int_{\text {absorbed heat }} T d S}{\oint T d S},
$$

where the integral in the denominator is restricted to portions of the cycle corresponding to net positive heating. For the loop considered here, the COP is approximately 13.2. A parcel of air executing such a path illustrates the function of a thermodynamic heat pump. The low-latitude Hadley cells act to convert thermal heat to kinetic energy, while the midlatitude Ferrel cells have the opposite effect.

\section{b. The power consumption rate of the Ferrel system}

With the same approach used to evaluate the key thermodynamic properties of the Hadley circulation, we calculated the power consumption rate, the COP, and heat absorption rate of the Ferrel cells in each hemisphere as well as their combination (Figs. 7-9). The annual mean power consumption associated with the overall Ferrel system amounts to $275 \mathrm{TW}$, consistent with the conclusion reached by Oort (1983) that the Ferrel system consumes kinetic energy at a rate larger than the rate at which power is produced by the Hadley system. The overall COP of the entire Ferrel circulation is relatively constant, approximately 12.1 for each month, with a relatively small associated variation with season. If the Ferrel system were allowed to circulate in the opposite direction as a thermal engine, its efficiency would be $1 /(1+\mathrm{COP})=7.6 \%$, significantly greater than that of the Hadley system. The average rate at which heat is absorbed from the cold area by the entire Ferrel circulation over the past 32 years amounts to approximately 3.3 PW. Heat is released at the warmer area of the Ferrel system at a rate of 3.6 $\mathrm{PW}(3.3 \mathrm{PW}+275 \mathrm{TW})$.

\section{Summary and discussion}

The Hadley, Ferrel, and polar circulations all contribute to the zonal mean kinetic energy budget of the atmosphere as illustrated by Fig. 10. The present study indicates an upward trend of the power generated by the Hadley circulation over the past 32-yr period. The analysis suggests that despite the apparent increase in the heat absorption rate, the thermodynamic efficiency of the Hadley circulation has remained relatively constant. Additional input of heat resulted, however, in a net increase in work performed and thus an increase in production of kinetic energy. The increase in the heat absorption rate over the period covered in this study amounted to $26.7 \mathrm{TW} \mathrm{yr}^{-1}$, or $0.1 \mathrm{~W} \mathrm{~m}^{2} \mathrm{yr}^{-1}$ averaged over the equatorial region dominated by the Hadley circulation $\left(30^{\circ} \mathrm{S}-30^{\circ} \mathrm{N}\right)$. The positive trend in the heat absorption rate generally follows the positive trend in 
surface temperatures observed between $23.6^{\circ} \mathrm{S}$ and $23.6^{\circ} \mathrm{N}$ (Fig. 5b).

Regarding the energetics of a Hadley cell, we conclude that, in addition to the absolute value of the mass streamfunction, the thermodynamic efficiency is an important factor in determining the power output. The thermodynamic efficiency is influenced by the profiles of temperature and pressure in the atmosphere. Observational analysis has shown that the Hadley circulation has undergone statistically significant poleward expansion in the past few decades ( $\mathrm{Hu}$ and $\mathrm{Fu}$ 2007). As the Hadley circulation expanded, the temperature and pressure profiles adjusted accordingly. The present results fail to indicate any statistically significant trend in the thermodynamic efficiency.

On the intensification of the Hadley circulation, both Mitas and Clement (2005) and $\mathrm{Hu}$ et al. (2005) found evidence for the intensification of the Hadley circulation in the NCEP-NCAR reanalysis. Since large absolute values of the mass streamfunction are normally associated with large power output of the Hadley system, the upward trend in the power output of the Hadley system indicated here is in general agreement with the conclusions from previous studies. Mitas and Clement (2006) pointed out that the trend might reflect systematic observational errors. Hu et al. (2011) argued that the increasing trend in the Hadley circulation strength in ERA-40 might be artificial as well. The MERRA data used in this study were processed in three separate streams. The data distribution adopted here used stream 1 for 1 January 1979-31 December 1992, stream 2 for 1 January 1993-31 December 2000, and stream 3 for 1 January 2001-present. Despite differences in the NCEP-NCAR used in the earlier studies and the MERRA data employed here, conclusions in both cases are in agreement with respect to the temporal intensification of the Hadley circulation.

The Ferrel circulation is an indirect meridional overturning circulation in midlatitudes. The rounder shape of $T-S$ cycle in Fig. 6d as compared to Fig. 1d confirms Lorenz's 1967 expectation that the stronger horizontal temperature contrast at midlatitudes should enhance the power consumption ability of the Ferrel system. The analysis implies that there has been no statistically significant trend in the power consumption rate of the Ferrel circulation over the past $32 \mathrm{yr}$.

The contribution of the Hadley and Ferrel circulations in combination have been responsible for net consumption of kinetic energy at an annually averaged rate of $77 \mathrm{TW}$ or $0.15 \mathrm{~W} \mathrm{~m}^{-2}$ over the past 32 years (Fig. 11). The polar meridional cell is too weak to allow its contribution to be calculated following the procedure adopted here for the Hadley and Ferrel systems. (a)

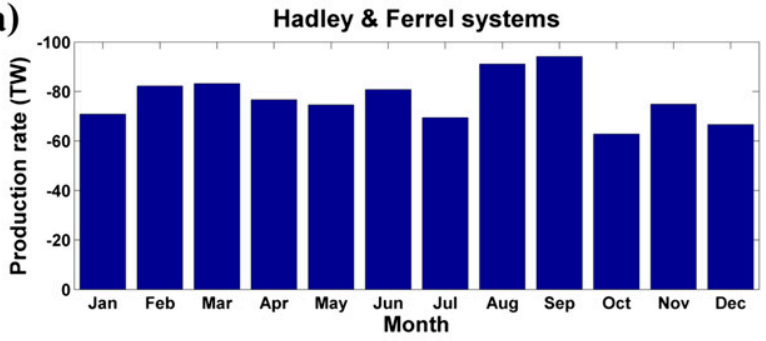

(b) Power production rate for Hadley \& Ferrel systems



FIG. 11. The power generated by the combination of Hadley and Ferrel circulations as a function of (a) month and (b) year from January 1979 to December 2010.

The polar circulation is direct; therefore, it is expected to contribute a net source of kinetic energy. Its contribution is unlikely to significantly offset the net sink attributed here to the combination of the Hadley and Ferrel systems.

Kim and Kim (2013) analyzed the Lorenz energy cycle using the standard daily output of MERRA dataset covering the period 1979-2008. Based on two different formulations, they estimated $C_{Z}$ to be either -0.06 or $-0.13 \mathrm{~W} \mathrm{~m}^{-2}$, which is in agreement with results obtained here.

Peixoto and Oort (1983) pointed out that $C_{E}$ is the dominant term in the creation of kinetic energy, and simplified the conversion from available potential energy to kinetic energy process as $P_{E} \rightarrow K_{E}$, and the zonal mean kinetic energy creation process as $K_{E} \rightarrow K_{M}$ (all symbols used here are defined in the caption for Fig. 10). Thus, they concluded that the energy cycle in the atmosphere proceeds from $P_{M}$ to $K_{M}$ through the scheme: $P_{M} \rightarrow P_{E} \rightarrow K_{E} \rightarrow K_{M}$. According to $\mathrm{Kim}$ and $\mathrm{Kim}$ (2013), $C_{K}\left(K_{E} \rightarrow K_{M}\right.$ process $)$ and $C_{E}\left(P_{E} \rightarrow K_{E}\right.$ process) amount to 0.33 and $1.45 \mathrm{~W} \mathrm{~m}^{-2}$, respectively, the absolute values of which are comparable to that of the power generated by the Hadley or Ferrel systems. This study provides a more comprehensive picture from $P_{M}$ to $K_{M}$ as summarized in Fig. 10.

Acknowledgments. The work described here was supported by the National Science Foundation. Junling 
Huang was also supported by the Harvard Graduate Consortium on Energy and Environment. We acknowledge helpful and constructive comments from Brian F. Farrell, Zhiming Kuang, Michael J. Aziz, and Xi Lu. We are also indebted to two anonymous reviewers for their helpful suggestions.

\section{REFERENCES}

Davis, S. M., and K. H. Rosenlof, 2012: A multidiagnostic intercomparison of tropical-width time series using reanalyses and satellite observations. J. Climate, 25, 1061-1078, doi:10.1175/ JCLI-D-11-00127.1.

Dima, I. M., and J. M. Wallace, 2003: On the seasonality of the Hadley cell. J. Atmos. Sci., 60, 1522-1527, doi:10.1175/ 1520-0469(2003)060<1522:OTSOTH $>2.0 . \mathrm{CO} ; 2$.

Frierson, D. M. W., J. Lu, and G. Chen, 2007: Width of the Hadley cell in simple and comprehensive general circulation models. Geophys. Res. Lett., 34, L18804, doi:10.1029/2007GL031115.

Grotjahn, R., 2003: Energy cycle. Encyclopedia of Atmospheric Sciences, J. A. Curry and J. A. Pyle, Eds., Academic Press, 829-841.

Hansen, J., R. Ruedy, J. Glascoe, and M. Sato, 1999: GISS analysis of surface temperature change. J. Geophys. Res., 104, $30997-$ 31 022, doi:10.1029/1999JD900835.

__, _- M. Sato, and K. Lo, 2010: Global surface temperature change. Rev. Geophys., 48, RG4004, doi:10.1029/ 2010RG000345.

$\mathrm{Hu}, \mathrm{Y}$., and Q. Fu, 2007: Observed poleward expansion of the Hadley circulation since 1979. Atmos. Chem. Phys., 7, 52295236, doi:10.5194/acp-7-5229-2007.

_, K. K. Tung, and J. Liu, 2005: A closer comparison of early and late-winter atmospheric trends in the Northern Hemisphere. J. Climate, 18, 3204-3216, doi:10.1175/JCLI3468.1.

_ C. Zhou, and J. Liu, 2011: Observational evidence for poleward expansion of the Hadley circulation. Adv. Atmos. Sci., 28, 33-44, doi:10.1007/s00376-010-0032-1.

_ - L. Tao, and J. Liu, 2013: Poleward expansion of the Hadley circulation in CMIP5 simulations. Adv. Atmos. Sci., 30, 790795, doi:10.1007/s00376-012-2187-4.

James, I. N., 1995: Introduction to Circulating Atmospheres. Cambridge University Press, $74 \mathrm{pp}$.

Johanson, C. M., and Q. Fu, 2009: Hadley cell widening: Model simulations versus observations. J. Climate, 22, 2713-2725, doi:10.1175/2008JCLI2620.1.

Kim, Y. H., and M. K. Kim, 2013: Examination of the global Lorenz energy cycle using MERRA and NCEP-reanalysis 2. Climate Dyn., 40, 1499-1513, doi:10.1007/s00382-012-1358-4.

Krueger, A. F., J. S. Winston, and D. A. Haines, 1965: Computation of atmospheric energy and its transformation for the Northern Hemisphere for a recent five-year period. Mon. Wea. Rev., 93, 227-238, doi:10.1175/1520-0493(1965)093<0227: COAEAI $>2.3 . \mathrm{CO} ; 2$.

Li, L., A. P. Ingersoll, X. Jiang, D. Feldman, and Y. L. Yung, 2007: Lorenz energy cycle of the global atmosphere based on reanalysis datasets. Geophys. Res. Lett., 34, L16813, doi:10.1029/ 2007GL029985.
Lorenz, E. N., 1955: Available potential energy and the maintenance of the general circulation. Tellus, 7,157-167, doi:10.1111/ j.2153-3490.1955.tb01148.x.

__ 1967: The Nature and Theory of the General Circulation of the Atmosphere. World Meteorological Organization, $109 \mathrm{pp}$.

Lu, J., G. A. Vecchi, and T. Reichler, 2007: Expansion of the Hadley cell under global warming. Geophys. Res. Lett., 34, L06805, doi:10.1029/2006GL028443.

Marshall, J., and R. A. Plumb, 2008: Atmosphere, Ocean, and Climate Dynamics: An Introductory Text. Academic Press, 74 pp.

Mitas, C. M., and A. Clement, 2005: Has the Hadley cell been strengthening in recent decades? Geophys. Res. Lett., 32, L03809, doi:10.1029/2004GL021765.

- , and — 2006: Recent behavior of the Hadley cell and tropical thermodynamics in climate models and reanalyses. Geophys. Res. Lett., 33, L01810, doi:10.1029/2005GL024406.

Nguyen, H., A. Evans, C. Lucas, I. Smith, and B. Timbal, 2013: The Hadley circulation in reanalyses: Climatology, variability, and change. J. Climate, 26, 3357-3376, doi:10.1175/ JCLI-D-12-00224.1.

Oort, A. H., 1964: On estimates of the atmospheric energy cycle. Mon. Wea. Rev., 92, 483-493, doi:10.1175/1520-0493(1964)092<0483: OEOTAE $>2.3 . \mathrm{CO} ; 2$.

_- 1983: Global Atmospheric Circulation Statistics, 1958-1973. University of California Libraries, 204 pp.

- - , and E. M. Rasmusson, 1970: On the annual variation of the monthly mean meridional circulation. Mon. Wea. Rev., 98, 423-442, doi:10.1175/1520-0493(1970)098<0423: OTAVOT $>2.3 . \mathrm{CO} ; 2$.

_ , and J. P. Peixoto, 1974: The annual cycle of the energetics of the atmosphere on a planetary scale. J. Geophys. Res., 79, 2705-2719, doi:10.1029/JC079i018p02705.

$\ldots$, and - 1983: Global angular momentum and energy balance requirements from observations. Advances in Geophysics, Vol. 25, Academic Press, 355-490.

Peixoto, J. P., and A. H. Oort, 1992: Physics of Climate. AIP Press, $160 \mathrm{pp}$.

Previdi, M., and B. G. Liepert, 2007: Annular modes and Hadley cell expansion under global warming. Geophys. Res. Lett., 34, L22701, doi:10.1029/2007GL031243.

Rienecker, M., and Coauthors, 2007: The GEOS-5 data assimilation system-Documentation of versions 5.0.1 and 5.1.0. NASA GSFC, Tech. Rep. Series on Global Modeling and Data Assimilation, Tech. Rep. NASA/TM-2007-104606, Vol. 27, 180 pp.

Seidel, D. J., and W. J. Randel, 2007: Recent widening of the tropical belt: Evidence from tropopause observations. J. Geophys. Res., 112, D20113, doi:10.1029/2007JD008861.

— Q Q. Fu, W. J. Randel, and T. J. Reichler, 2008: Widening of the tropical belt in a changing climate. Nat. Geosci., 1, 21-24, doi:10.1038/ngeo.2007.38.

Stachnik, J. P., and C. Schumacher, 2011: A comparison of the Hadley circulation in modern reanalyses. J. Geophys. Res., 116, D22102, doi:10.1029/2011JD016677.

Wiin-Nielsen, A., 1967: On the annual variation and spectral distribution of atmospheric energy. Tellus, 19, 540-559, doi:10.1111/ j.2153-3490.1967.tb01507.x. 